\title{
Structural holes, knowledge intermediaries and evolution of the triple helix system with reference to the hard disk drive industry in Thailand
}

\author{
Karantarat Nakwa* and Girma Zawdie** \\ *National Science and Technology Development Agency, Thailand; **University of Strathclyde, UK
}

\begin{abstract}
This paper explores the evolutionary process underlying the development of the triple helix innovation system and the role of knowledge intermediaries in the process. It draws on the experience of knowledge network development in an SME cluster in the Thai hard disk drive industry. Conceptually, the evolutionary process starts with inter-firm networks, which occur in the form of supply chain-based vertical links and trade association or cluster-based horizontal links. These evolve into triple helix networks and culminate into the triple helix innovation system through the agency of network dynamics. Intermediaries enhance network development as sponsors, providing funds; as brokers, closing and bridging structural holes that disconnect network players; and as boundary spanners, facilitating knowledge circulation. The case study suggests that knowledge network development in Thailand has a long way to go before morphing into the triple helix innovation system. Some evidence of network dynamics was nonetheless detected; but for lack of trust in the triple helix culture, the fledgling network dynamics fizzled out when the government prop, which initiated the process, was withdrawn. The paper concludes by highlighting the need for policy to promote the culture of trust among network players and for knowledge intermediaries to be less ad hoc and more systemic in their organisation and operation.
\end{abstract}

Keywords: Triple Helix; network development; innovation system; intermediaries; structural holes; learning; knowledge circulation; trust; hard disk drive industry; Thailand

\section{Introduction}

The aim of this paper is twofold: to show the development of triple helix knowledge network as a basis for the evolution of the triple helix innovation system; and knowledge intermediaries as policy vehicles for network development through the bridging and closing of 'structural holes'. An important distinction is thus drawn between 'triple helix' as a knowledge network and 'triple helix' as a system of innovation. This is particularly relevant to discussions of triple helix in the context of developing countries where, for reasons relating to prevailing socio-economic and cultural conditions, policy would be rather more effective pursuing development of the former than the latter as a matter of priority.

The triple helix knowledge network is an evolving phenomenon in developing countries. This is reflected in the growing policy support for the expansion of 
university-industry cooperation. However, what little university-industry interaction there has been to date in developing countries has for the most part been driven by personal initiatives and conducted on ad-hoc basis. Much of the problem underlying this situation relates to shortfalls in institutional capacity development in these countries. For this problem to be overcome, and for developing countries to benefit from integration of the activities of knowledge creation and knowledge use, the role of policy in knowledge network development would help to mitigate the effects of institutional rigidities and the fragmentation of activities in the domains of knowledge production and use. The question, however, remains: how effective are governments in developing countries in playing interventionist roles to leverage the evolution of triple helix knowledge networks? Given the widely acknowledged failure of both governments and markets in the allocation and management of resources in developing countries, the question at stake is how best the mechanisms of intervention can be designed to promote the development of a sustainable institutional framework for knowledge production and its use.

This paper aims to look into the significance of the roles of innovation intermediaries in bridging and closing 'structural holes' that disconnect actors in the triple helix network (Burt, 2000, 2001, 2004), with particular reference to the case of a cluster of SMEs in the Thai hard disk drive (HDD) industry. 'Structural holes' prevail in the absence of well-developed networks, leaving firms disconnected and compartmentalised, and so without network safeguards against the risk of exposure to adverse business situations in which opportunistic behaviour and free-riding possibilities abound. 'Structural holes' thus create a barrier against knowledge exchange; and this would add to the transactions cost of firms and make them rather reluctant to innovate, lest they be hostage to free-riders. Where 'structural holes' 
abound, they constrain the process of knowledge transmission and the evolutionary process in the development of knowledge networks. But they also offer opportunities for network development and policy initiatives to promote institutional capacity building as a basis for innovation, technological progress and socio-economic development.

Thailand is one of the rapidly emerging developing countries aspiring to qualify as an 'Asian tiger' economy. In the past, economic growth in Thailand derived from the accumulation of foreign direct investment (FDI) (Diao et al., 2006). However, in recent years, the government has come up with policy initiatives to shift the economy from an FDI-based to a knowledge-based growth trajectory (Promwong, 2001). Consequently, the cluster approach has been adopted since 2004 to develop and upgrade technological capabilities through the promotion of networking within and between industries and complementary institutions, namely universities, research centres and government and non-government agencies. The focus of this paper is on a specific aspect of the industrial development experience of Thailand as a point of reference for analysing the role of intermediaries in the formation and evolution of triple helix networks that constitute a strategic basis for knowledge creation, knowledge exchange, knowledge use and the development of a triple helix innovation system.

The remainder of this paper is four parts. The part following this introduction discusses the conceptual framework, including review of the evolution of inter-firm networks into triple helix innovation system; the characteristics and significance of structural holes in networks; and the roles played by innovation intermediaries in the transformation process. The third part briefly describes the method used in this study. The fourth part presents a case study drawing on the network experience of the Thai 
hard disk drive (HDD) industry. The last part presents the conclusions and policy implications of the issues raised in the paper.

\section{Conceptual framework}

\subsection{Evolution of triple helix innovation system}

Triple helix knowledge networks would conceptually be expected to derive from 'preexisting inter-firm networks', including vertical supply chain and horizontal industrial association networks (Nakwa et al., 2012). Knowledge networks can be categorised into three dimensions (Pöyhönen and Smedlund, 2004; Nakwa et al., 2012). First, horizontal industrial networks consist of firms in the same industry or at the same level of value chain. Firms in the same industry with similar knowledge base can reduce the costs and lead times of technological development through the coordination of efforts in some common areas of activity (Robertson and Langlois, 1995). Second, vertical value chains involve trading relationships of firms with suppliers and customers. Both suppliers and customers influence technological development at the level of the firm. Customers exercise this influence through the expression of their requirements (Gemünden et al., 1996), and suppliers, through the adoption of new technologies thereby changing the supply chain dynamics (Freeman, 1991). The third category of inter-firm relationship, which occupies the diagonal space (see Figure 1), combines the vertical and horizontal elements as components of the institutional sphere of production and wealth creation. The evolution of this sphere is conditional on its alignment to the overarching knowledge and policy and governance spheres.

Vertical and horizontal inter-firm networks predate triple helix networks and are referred to in this paper as 'pre-existing networks'. Of their own, such networks offer limited scope for growth and deep cooperation. This is because the firms within 
them do rarely come with diverse knowledge and resource profiles and have limited exposure to sources of new ideas. Network development through knowledge exchange has, however, its own dynamics, which cuts across knowledge boundaries to involve heterogeneous players. These are represented occupying the diagonal space in Figure 1. Conceptually, the triple helix knowledge network derives from the integration of activities originating from horizontal industrial networks, vertical value chain networks and other supporting institutions from the knowledge and policy and governance spheres (see Figure 1).

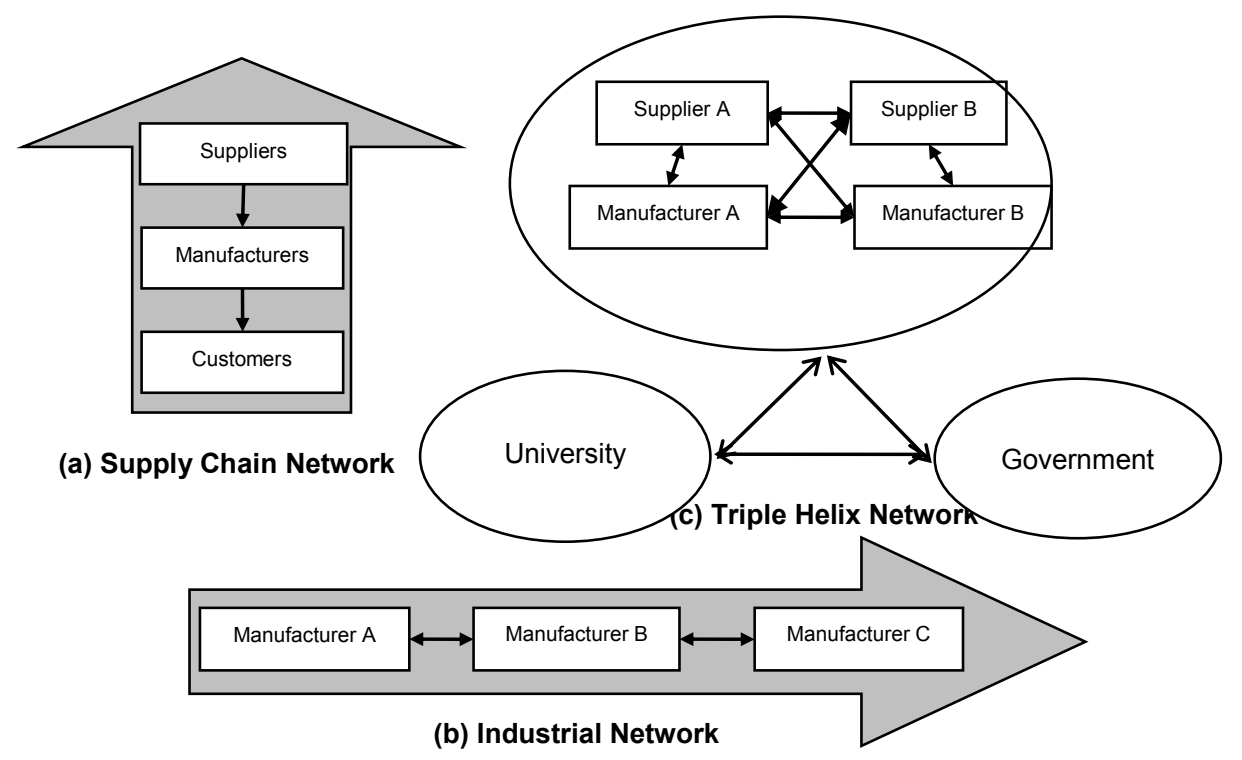

Figure 1: Innovation networks (a) Supply chain network (b) Industrial Network (c) Triple helix network

This type of knowledge network, which exposes firms to a wide range of actors with a diverse set of knowledge content and structure, experience, competencies and resources, has the potential to generate network dynamics (Nakwa et al., 2012). Interactions between firms across different value chains and industries and with different technological paths can open new technological opportunities that provide the basis for radical innovation (Pyka, 2002). Apart from inter-firm cooperation, the interactions along the diagonal space would be expected to involve other institutions, 
such as universities and government agencies. These two institutional players together with industry and business make up the triple helix network. Universities are knowledge producers feeding networks with new knowledge categories. Business and industry use the knowledge they acquire to create wealth; and the role of government is to provide resources and policy and institutional mechanisms to broaden and deepen inter-firm networks and to stimulate knowledge circulation across institutional boundaries (Gemünden et al., 1996). The combination of diverse knowledge strands along the diagonal space generates network dynamics that are capable of bringing forth new technological paradigms and trajectories (Dosi, 1982; Menzel and Fornahl, 2007; Leydesdorff and Zawdie, 2010).

Networking between triple helix institutional actors enhances the learning process and contributes to the development of a dynamic culture of creativity and innovativeness. This happens because networking allows the convergence of diverse knowledge streams, which is necessary for the synthesis of ideas to culminate in innovation (Balthasar et al., 2000; Madill et al., 2004; Knorringa and van Staveren, 2006; Capaldo, 2007; Menzel and Fornahl, 2007). It is this synthesis of heterogeneous knowledge streams that constitutes network dynamics underlying the process of knowledge conversion and creation in the triple helix system.

According to Nonaka and Takeuchi (1995), knowledge creation involves a dynamic learning process in which tacit knowledge is converted to explicit knowledge through socialisation, externalisation, combination and internalisation. Through these iterative processes, the knowledge of individuals can be combined to create group, organisational and inter-organisational knowledge in successive loops of learning, thus adding to the knowledge stock of organisations that function as network players (Bell and Albu, 1999; Gilsing, 2005). It is through networking that the diverse and 
non-redundant knowledge streams and competencies of heterogeneous actors are combined to provide the basis for the emergence of network dynamics and for the occurrence of innovation ( Gilsing, 2005; Beckman and Haunschild, 2002).

However, for firms to learn from institutional players with different cognitive backgrounds, they would need to enhance their absorptive capacities through investments in equipment, machinery and human resource development (Gilsing, 2005). These would enable them to create a common cognitive framework; build trust and mutual understanding among themselves; and exchange their tacit knowledge through socialisation in such forms as cross-licensing. Newly combined knowledge categories at organisational and inter-organisational levels are significant for their contribution to total productivity growth across the economy.

The depth of knowledge created by a firm as a network player depends on the level and mode of organisational learning, which in turn depends on the cognitive distance of the sources of knowledge. Thus, within a knowledge network where there is cognitive closeness, which offers scope for 'strong ties', firms would engage in 'single loop' learning (Argyris and Schoen, 1978). Single loop learning results in the effective use of acquired knowledge through a somewhat linear process of downloading and redesigning. In this mode, the learning organisation's existing norms, procedures, policies and goals are not challenged and modified. Learning is at best 'adaptive' and 'non-strategic' (Mason, 1993). Not surprisingly, this model of linear learning hardly adds to the depth and breadth of organisational knowledge. Nor does it involve shifts in knowledge paradigms.

On the other hand, knowledge transactions across networks are complex and non-linear and would rather conform to the 'double loop' and 'triple loop' learning modes, which turn on awareness of knowledge gaps (Nevis et al., 1995); call for the 
introduction of new structures and strategies for learning (Argyris et al, 1985; Argyris, 1992, 1994; Flood and Romm, 1996; Snell and Chak, 1998; Pahl-Wostl , 2009); and have, therefore, the potential of producing incremental and radical innovation. Thus, the 'double loop' and 'triple loop' modes constitute the essence of dynamic learning, which enables firms to create, extend or modify and hence deepen and widen their knowledge base by reconfiguring and realigning their learning routines to changes in the wider context of business and policy environments that bear on their organisation and management systems. As such, dynamic learning is essentially geared to the processes of knowledge exploration, knowledge assimilation and knowledge exploitation (Lewin et al., 2011). These are processes that would be expected to arise in the bridging and closure of structural holes.

\subsection{Structural holes: closure and bridging}

The effective combination of knowledge deriving from heterogeneous actors is constrained by differences in the culture and knowledge base of the network players; and also by institutional rigidities arising from the prevalence of structural holes. These constraints are mitigated by the intervention of intermediaries to close and bridge structural holes through the formation of 'strong ties' and 'weak ties' (Burt, 2001). When intermediaries close structural holes among firms with knowledge proximity, they create 'strong ties' that provide the scope for intra-industry collaboration akin to the inter-firm horizontal network in Figure 1. When they span across knowledge boundaries to bridge structural holes, they create 'weak ties' that provide firms access to new and diverse knowledge sources.

Structural holes occurring among firms within spheres of knowledge proximity are categorised 'internal'; and those that occur among firms and organisations between knowledge spheres are categorised 'external' (Burt, 2001; Gilsing, 2005). 
Internal structural holes among firms with knowledge proximity arise from the lack of trust. Where internal structural holes prevail, firms would be unwilling to share knowledge with one another. This situation leads to a sub-optimal level of knowledge circulation among firms within the knowledge sphere and hence to sub-optimal levels of network capital and technological capability development (Johnson, 2009). Intermediaries can close these internal structural holes and transform them into strong ties that provide the basis for micro knowledge circulation (Ahuja, 2000; Etzkowitz and Dzisah, 2008). Knorringa and van Staveren (2006) refer to this closure process as 'bonding social capital'.

External structural holes arise due to differences in culture, resources, competencies and knowledge profiles between players in different institutional spheres or knowledge networks. These differences may enhance cognitive distance and keep firms far apart; but network players would use these as potential sources of new and non-redundant knowledge. But for this to happen, intermediaries would be expected to bridge external structural holes (Burt, 2000) and transform them into 'weak ties' that provide the basis for macro knowledge circulation (Etzkowitz and Dzisah, 2008) and create the opportunity for innovation through the combination of heterogeneous knowledge categories (Nonaka and Takeuchi, 1995; Pyka, 2002; Knorringa and van Staveren, 2006).

As can be seen in Figure 2, a triple helix network contains both strong and weak ties. Strong social capital within institutional spheres facilitates communication and collective actions; and the complementarity of heterogeneous actors with different knowledge profiles provides the condition for new knowledge creation and innovation. 


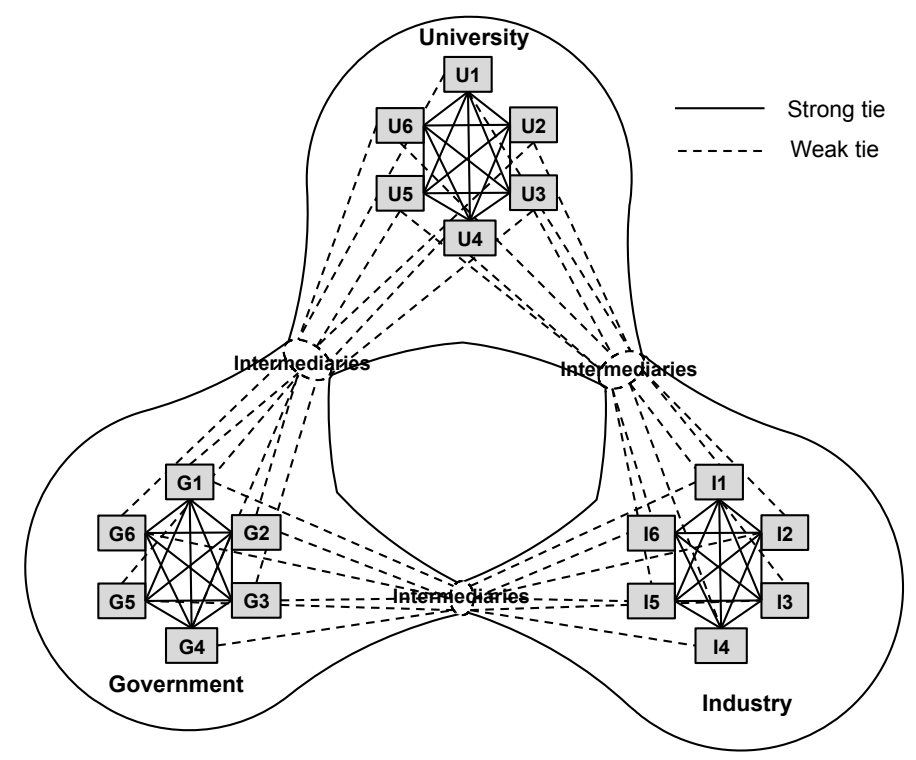

Figure 2: Network closure within institutional actors and brokerage between institutional actors in triple helix

\subsection{Roles of intermediaries in promoting triple helix networks}

Triple helix networks are dysfunctional where 'structural holes' remain unclosed and unbridged. Intermediaries are in this case necessary to transform inter-firm networks into triple helix networks by bringing other institutional actors, like universities and government agencies, into the picture (Nakwa et al., 2012). In this transformation process, intermediaries play roles as sponsors, providing guidelines and funds to promote network development; as brokers, linking actors and building collaboration mechanisms; and as boundary spanners, providing operational services to facilitate knowledge circulation. Intermediaries can also play these roles in the evolution of triple helix networks into triple helix system by stimulating the emergence of network dynamics through the closing and bridging of structural holes.

Intermediaries play a sponsoring role by providing funding to create collective actions for building trust, thus closing internal structural holes. They would also promote the case for investments in machinery and equipment and human development as a strategy for reducing cognitive distance or differences between 
actors in different institutional spheres, thus bridging external structural holes. They play a brokering role by connecting internal structural holes and creating collective actions within institutional spheres, and also by connecting external structural holes through specific investments in human resource development and the acquisition of new software and hardware technologies that have the effect of improving the absorptive capacities of network players. They play a boundary-spanning role by providing operational services that: (1) facilitate the exchange of tacit knowledge of actors within institutional spheres through socialisation; (2) convert tacit knowledge shared by players within institutional spheres into explicit knowledge through externalisation; (3) help upgrade technological capability of network players across knowledge boundaries by reducing cognitive distance and replacing them with weak ties, thus stimulating combination of the diverse knowledge strands of heterogeneous actors; and (4) help commercialise newly combined knowledge or innovation, thus creating economic value through 'internalisation' (Nonaka and Takeuchi, 1995; Nakwa and Zawdie, 2012).

In addition, intermediaries are instrumental in the creation of network dynamics through the iterative transformation of knowledge within triple helix networks. This iterative transformation involves knowledge exploration across 'weak ties' and knowledge exploitation within 'strong ties' (Capaldo, 2007; Harryson et al., 2008) within the triple helix network (see Figure 3). Intermediaries can stimulate knowledge exploration across networks through socialisation and externalisation, thereby transforming 'compartmentalised networks' with structural holes into 'loosely connected networks' (Gilsing, 2005). The process of knowledge exploitation involves learning through the combination of diverse categories of knowledge, and the subsequent internalisation and commercialisation of these by individual firms, thus 
providing the basis for the next round of knowledge exploration and knowledge exploitation (Nonaka and Takeuchi, 1995).

Intermediaries thus set in motion the network dynamics in which 'strongly connected networks' turn to 'compartmentalised networks' to capture new 'structural holes' and continue the process of knowledge combination and innovation on a sustainable basis (see Figure 3).

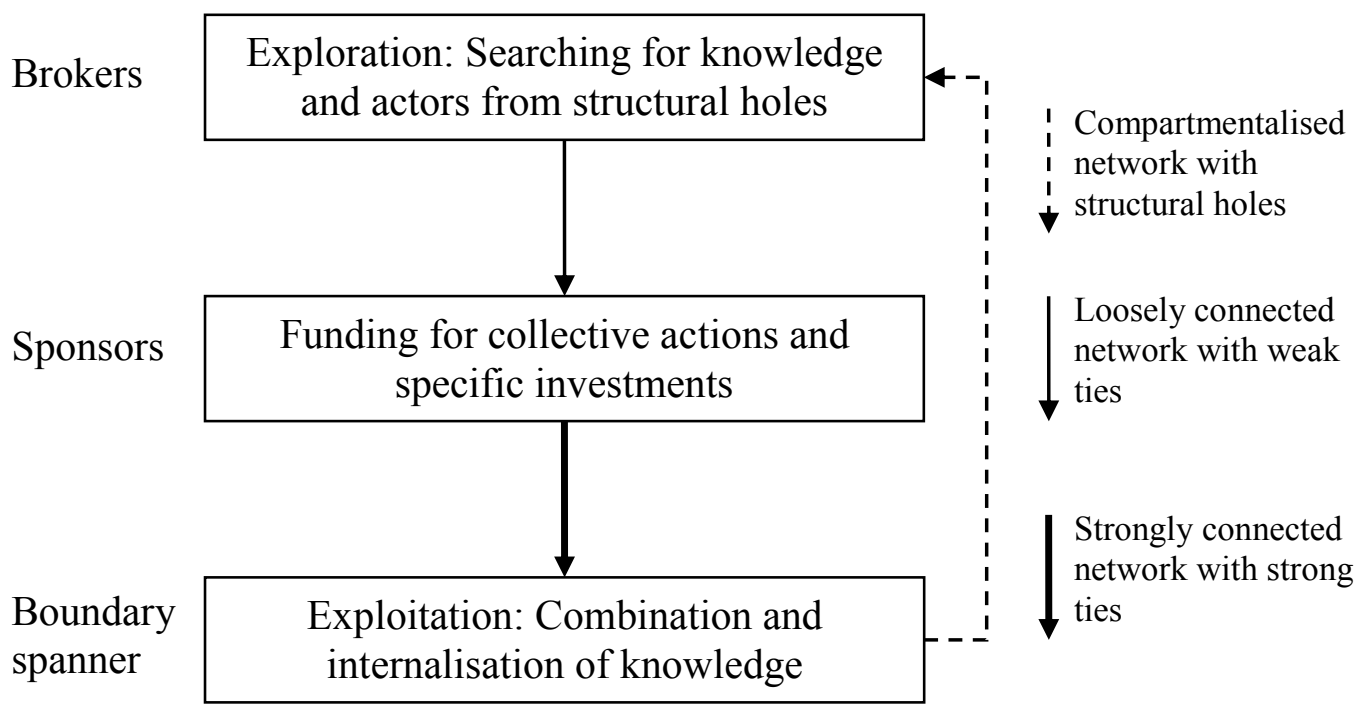

Figure 3: Roles of intermediaries in stimulating network dynamics through the closure and bridging of structural holes

\section{Methodology}

This paper is part of a larger study on knowledge network development in Thailand funded by the Thai Royal Government (Nakwa, 2013). The paper makes use of the hard disk drive (HDD) industry as a case study. The HDD industry was selected on grounds that it was one of areas where MNCs operate in Thailand, and is as such considered to be of strategic significance in view of the Government's policy commitment to promote the incorporation of local SMEs into the global value chains of MNCs through the intervention of knowledge intermediaries. 
The study is of the explorative type, and the method of analysis is essentially qualitative. Data collection for the study was conducted mainly through interviews of prominent individuals representing organisations and institutions based on the snowball sampling method. The interview-based survey was conducted intermittently between February and August 2012 as part of the wider industry study (Nakwa, 2013). First, an intermediary organisation closely linked with the activities of the HDD sector was identified, and a key individual representing the organisation was selected to elicit information on the experiences of intermediaries in the process of network building and brokering relationships between triple helix actors. The individual from the intermediary organisation was also asked to suggest names of key persons from academic, government and industrial sectors who would be knowledgeable enough to speak about the role of their respective institutions in network formation and in the process of knowledge exchange along the triple helix network. Interviewees were contacted to make appointments for face-to-face interviews. All but one offered to be available for face-to-face interviews. The interviews took about 45-60 minutes. The one respondent who would not be available for face-to-face interview however agreed to be available for telephone interview. In all, five individuals were interviewed. Moreover, pertinent archival documents, including annual plans and reports and observation notes were employed as sources of data.

The interviews involved questions that were semi-structured and open-ended. The questions asked sought to explore the experiences of interviewees in the formation and operation of networks and the roles of the interviewees and their institutions. They also queried the roles and motivation of interviewees in the process of network formation and as to how long they were engaged in the process. In addition, 
individuals were asked about the roles, activities and knowledge exchange efforts of important network actors other than the organisations they represented. Interviewees were also asked to identify intermediaries in their networks; to assess the capabilities and resources of such intermediaries; and to evaluate the state of network development, the problems and obstacles of network management and the directions in which the networks were likely to evolve.

The data obtained from the interviews was synthesised and used as a basis for an analytical discussion of a case study relating to an HDD manufacturing MNC and a cluster of SMEs organised to function as one of its suppliers. The analytical discussion is based on the conceptual framework developed in this paper. The case study method used in this study provides details of real-life events that would help bring out the complex features underlying the experiences in network formation and its management.

In the following section of this paper, the case study method is used in which the issue of triple helix network development is qualitatively analysed based on a synthesis of information drawn from the interview-based survey. The case study approach is used to provide a contextual understanding of the evolution of the triple helix system in the Thai industrial sector, in general, and the HDD sub-sector, in particular.

\section{The case of HDD industry in Thailand}

\subsection{Current status of Thai HDD industry}

Thailand is the largest manufacturing base of HDD industry in the world. In 2010, it held a 42 per cent market share of world production with export value at 596,677 million baht (approximately 20,000 million USD) (see Table 1). As can be seen from Table 1, HDD products and parts account for about one-third of the export of the 
electronics industry, which is the second largest industry of Thailand. The HDD industry and its support industries create approximately 150,000 jobs (CPMO, 2011). In addition to its contribution to industrial employment and output, the HDD industry contributes to the development of technological capability in Thailand by providing a basis for international technology transfer to the country.

Table 1: Production and export of Thai HDD industry

\begin{tabular}{|l|c|c|c|c|c|}
\hline & 2006 & 2007 & 2008 & 2009 & 2010 \\
\hline Production volume (million pieces) & 152.8 & 204 & 247.2 & 258.2 & 280.6 \\
\hline Production growth (\%) & - & 33.5 & 21.2 & 4.4 & 8.7 \\
\hline $\begin{array}{l}\text { Export of HDD products and parts } \\
\text { (million Baht) }\end{array}$ & 559,739 & 597,059 & 605,314 & 545,468 & 596,677 \\
\hline $\begin{array}{l}\text { Proportion of HDD export to } \\
\text { electronics export }\end{array}$ & 35.7 & 36.2 & 37.4 & 37.6 & 35.2 \\
\hline Market share (\%) & N/A & N/A & N/A & 44 & 42 \\
\hline
\end{tabular}

Source: Cluster and Programme Management Office, NSTDA (CPMO, 2011)

Although Thailand has long been the manufacturing base of most HDD makers, the value added created in the in the industry accounts for about one per cent of the total HDD export value (Kohpaiboon, 2009). Most HDD makers and their first tier suppliers are MNCs who chose to invest in Thailand to take advantage of the low wage regime in the country. Local firms do not have the capability to produce HDD parts due to lack of infrastructure for implementing high precision technology.

Cluster development policy has been pursued in Thailand since 2006 with the aim to promote the development, inter alia, of the HDD industry. The Hard Disk Drive Institute (HDDI), a hybrid organisation, was established following consultations between representatives of industry, government agencies and universities to formulate mechanisms for collaboration and for the management of the HDD cluster. During the first phase of the HDD cluster development (2006-2010), emphasis of policy was on three technological development activities, including human resource development, $R \& D$ and supply chain development (see Figure 4). 
Both government and industry played major roles in human resource development that provided the basis for upgrading the technological capability of firms in the HDD and the support industries. It can be seen from Figure 4 that the value of government support for R\&D and supply chain development activities was significantly more than the matching support provided by industry.

During the second phase of cluster development, government support was specifically targeted to achieve deeper technological development in HDD production and also in the production of automated equipment by the local SMEs on the HDD supply chain (CPMO, 2011). The case study of TH Alliance discussed below was used as a pilot project for developing a supply chain system to serve MNCs and enhance the value added effect of investment in HDD production.

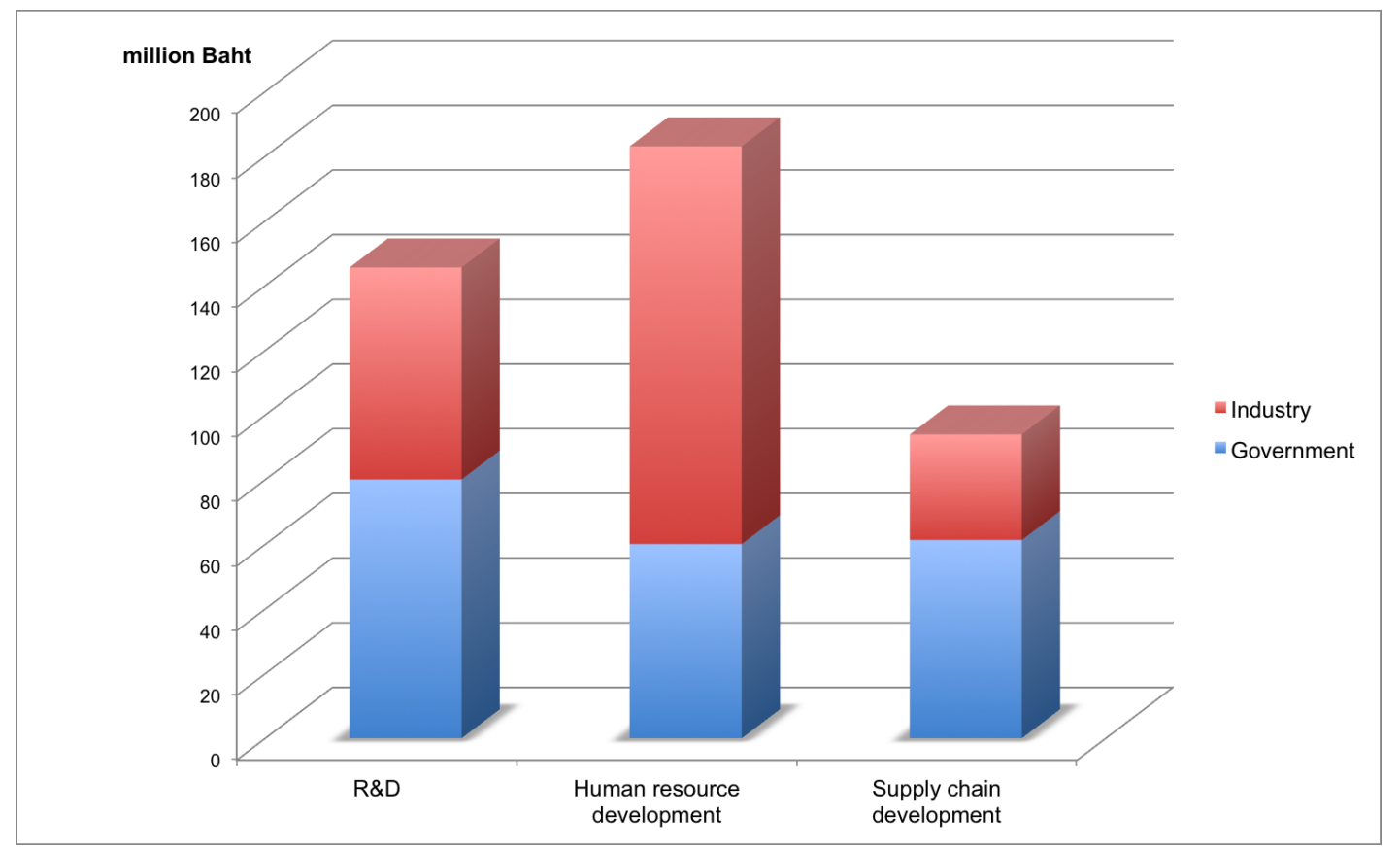

Figure 4: Government support for network development in HDD industry and industry matching fund

Source: Cluster and Programme Management Office, NSTDA (CPMO, 2011)

\subsection{Case study: TH Alliance as a triple helix network}

\subsubsection{Establishment of TH Alliance}


TH Alliance is a pilot project involving the horizontal integration of four local SMEs engaged in the manufacturing of automative products. It was initiated as a cluster by the Hard Disk Drive Institute (HDDI) to serve as a supplier to the HDD maker, and so to enhance the backward linkage effect of the HDD industry., The HDDI also set up Industry/University Cooperative Research Centres (I/UCRCs) as brokering intermediaries in three universities to with the aim to integrate the activities of local SMEs into the supply chain of the HDD makers.

The Institute of Field Robotics (FIBO) in King Mongkut's University of Technology, one of the three I/UCRCs, identified a list of potential local firms with the basic capability to manufacture automative products. It provided the list to an HDD maker to select potential suppliers to establish an alliance of local firms by integrating their production lines in order to enable them achieve economies of scale. Four SMEs were selected to establish TH Alliance to provide automation products for an HDD maker. Some of the SMEs had competitive advantage in manufacturing capability and others in design capability. The four SMEs in the TH Alliance set out their machines in particular lines to form a joint station at a site near an HDD maker. Then, as a boundary-spanning intermediary, FIBO facilitated knowledge circulation between MNCs and local SMEs by providing research support to the local firms. This offered the local firms opportunities for reverse engineering and the acquisition of knowledge that would enable them to replicate some imported machines and develop their technological capabilities in the process.

\subsubsection{Role of intermediaries}


The 'pre-existing networks' of the HDD industry in Thailand involve inter-firm networks - i.e. the vertical value chain between HDD makers and MNC suppliers; and a horizontal industrial association represented by the Thai branch of International Disk Drive Equipment and Materials Association (IDEMA), which was established by four HDD makers to develop human resources and share information about global trends of the HDD market. Prior to intervention by the HDDI, the MNCs manufacturing HDD would not trust the local SMEs because the local firms were were perceived to be too risky to do business with in the absence of any institutional and organisational safeguards or network capital. Moreover, they lacked quality assurance, inspection equipment and the ability to produce very high precision products.

The triple helix network that developed around the HDD industry was at best rudimentary. Few universities had forged links with the MNCs in the industry in the form of contract research. A government agency, namely the Thailand Board of Investment, provided tax incentives for technology and human development activities of these MNCs. However, this compartmentalised network with both internal and external structural holes did not promote value creation and technological capability development due to the absence of knowledge circulation. Consequently, the knowledge stock of local firms hardly increased (Bell and Albu, 1999). Against this background, industrial policy sought to stimulate technological capability development in SMEs by integrating them into global supply chain systems through association with MNCs and also by actively engaging them in knowledge transactions with other firms and local institutions as network players. This arrangement, which would benefit SMEs to tap into the global knowledge network, was implemented by intermediaries through the bridging and closure of structural holes. 
Prior to the establishment of $\mathrm{TH}$ Alliance as a consortium, there were four SMEs who knew each other as firms in same industry, albeit informally and without any intention to cooperate. These four SMEs, set apart from one another, featured evidence of internal structural holes. The Thai Government set up the HDDI, which, as a sponsoring intermediary, assigned FIBO as a brokering intermediary to propose the establishment of TH Alliance and to create mechanisms for collaboration. HDDI then provided funding for FIBO to play a boundary-spanning role, providing technical assistance for the SMEs constituting TH Alliance to work on the joint project. Thus by acting as sponsors, brokers and boundary spanners, intermediaries sought to connect internal structural holes, and so to incorporate the SMEs into a knowledge network that would ensure their knowledge stock is continually refreshed.

Prior to the formation of TH Alliance, the SMEs did not have any links with universities. For HDDI, this represented an external structural hole to be bridged. As a broker, FIBO invited the local SMEs to participate in the supply chain development programme with the aim to identify potential firms to work with MNCs. The selected SMEs were trained by FIBO and were financially supported by HDDI to develop upstream products for the production of HDD. Through this bridging process, FIBO played an essential role as a broker in transforming external structural holes into 'weak ties' through the formation of a knowledge network between the four selected SMEs, an MNC, HDDI and FIBO itself. FIBO also operated as a boundary spanner promoting the circulation of knowledge among the SMEs.

\subsubsection{Roles of weak and strong ties in creating network dynamics}


Network dynamics arise from iterative processes of knowledge creation and combination consequent upon interactions between heterogeneous actors on the knowledge network. In the case of TH Alliance, intermediaries played three roles in transforming compartmentalised networks into a more coherent network through the bridging and closure of structural holes. In its role as a sponsoring intermediary, HDDI supported 'specific investments' to reduce the cognitive distance between the four SMEs, the client MNC and FIBO through the collaborative mechanisms created by FIBO as a broker. These 'specific investments' were directed, inter alia, at human resource development to upgrade the technological capability of engineers in the four SMEs. In addition, FIBO exercised a boundary-spanning role by providing training and technology transfer services to SMEs to enable them to participate in the supply chain of the MNC. The MNC was consequently connected to the four SMEs through the specification of its demand for intermediate products. Socialisation between FIBO, the four SMEs and the MNC occurred in these collaborative activities, transforming the compartmentalised network into a loosely connected network.

Other modes of knowledge conversion related to the exploitation of knowledge which occurred through the iterative processes of externalisation, combination and internalisation. With the supportive intervention of intermediaries, these processes would result in the transformation of loosely connected networks into strongly connected networks. As a brokering intermediary, FIBO promoted the creation of links among players including the four SMEs in TH Alliance and the MNC. FIBO also used its resources and boundary spanning expertise to facilitate knowledge conversion processes within the production sphere. For example, in the externalisation process, FIBO researchers helped firms to conduct reverse engineering of imported machines used by an HDD maker and transferred this knowledge and blueprint to the 
four SMEs in TH Alliance. The SMEs in TH Alliance would then claim intellectual property rights (IPR) on the new automotive products, deriving from a synthesis of the reverse engineering process. The SMEs integrated their production lines to produce the patented machines. HDDI provided financial support for the building of prototypes; and FIBO assisted in the production of documents for quality certification that would enhance the profiles of local firms and their eligibility to participate in the supply chains of MNCs. At the end of the project, the MNC purchased seven of the ten patented machines produced by the SMEs. Thus, the first loop of knowledge creation saw the individual knowledge strands of FIBO and the four SMEs combined into inter-organisation knowledge, creating new knowledge and product innovation.

However, there is no evidence of continuity in the knowledge conversion and creation cycle ratchetting up in a spiral mode as postulated by Nonaka and Takeuchi (1995). This appears to suggest that the network dynamics created in by the SMEs in TH Alliance was not robust enough to be sustained. A major problem behind this state of affairs is the lack of trust or social capital among players in the network that prompted the MNC not to be readily forthcoming in its relationship with the SMEs, in the first place. This problem was later exacerbated by the reduction of government support for network development.

After selling its patents to the HDD maker as exclusive user, TH Alliance was unable to further reproduce and sell those seven innovated machines to other HDD makers and other manufacturers in other industries. This left TH Alliance with the option to bid for new projects and develop new machines. However, some members of the Alliance felt that they did not derive any benefits from the business of the Alliance and were reluctant to continue their being part of it. This could happen because the establishment of $\mathrm{TH}$ Alliance was underpinned not by trust among the 
local firms but by transient pecuniary incentives induced by the provision of government support (Murdoch, 2000). Nor was there much trust between the SMEs and the $\mathrm{MNC}$, their client. In other words, the socialisation process in this project did not really help to reduce the cognitive distance between the SMEs themselves and between the SMEs and their client MNC. For all that, the system thrived, if unsustainably, with knowledge flowing in one direction from FIBO to the SMEs. Eventually, when the Government withdrew its support - perhaps more for budgetary reasons than for lack of interest in knowledge network development - TH Alliance ceased to function as an effective network player; and the knowledge creation loop was aborted after the first round of activities of socialisation, externalisation, combination and internalisation that culminated in the sales of seven innovated machines to the MNC. Thus, the network dynamics, which appeared to have had a promising start, failed to sustain the cumulative process of knowledge creation through the mechanism of learning by socialisation, externalisation, combination and internalisation.

Following the cut in government support and disengagement of the $\mathrm{MNC}$, the SMEs regrouped to develop strong ties and create a new alliance to combine knowledge and innovate. Thus, on the back of acquired experience, two of the SMEs started a new alliance to bid for new projects from the same HDD maker. Another SME partnered with an overseas company to establish a joint venture as a basis for technology transfer. Such enterprising initiatives show some evidence of learning from experience. However, without ready access to sources of knowledge production, inter-firm networks face the risk of being locked into old trajectories that would make it difficult for firms to engage in the knowledge combination process through the closure and bridging of structural holes. 
For network development to be effective, the intervention of intermediaries is crucial. Thus, the link the HDDI helped to create between the four SMEs and the university-based intermediary, FIBO, would need to be strengthened, but on the basis of mutual trust and not merely on the back of government support. Trust would provide the basis for the SMEs to have sustainable access to sources of knowledge production, and for FIBO and similar intermediaries to be agents for the development of entrepreneurial university culture.

\section{Conclusions and policy implications}

This paper has attempted to shed some light on the significance of the roles of knowledge intermediaries in the evolution of triple helix network into triple helix innovation system. As already discussed, this evolutionary process occurs through the bridging and closure of structural holes. In developing countries, where triple helix networks are characteristically dysfunctional, intermediaries are necessary to bridge and close structural holes and then to nurture and grow them into weak and strong ties. Intermediaries can also stimulate the emergence of network dynamics through the bridging of compartmentalised networks of heterogeneous players.

The case study of TH Alliance discussed in this paper shows that intervention of intermediaries based on short-term-oriented government funding may, in the best of circumstances, help produce the first cycle of knowledge creation and network transformation that, however, may not be robust enough to produce the drive for subsequent cycles. The evidence deriving from the case discussed in this paper shows that the subsequent cycles of knowledge creation and network transformation would be aborted in the absence of trust and possibly also the provision of government support. It is also apparent from the case that top-down policy could not be expected to create real trust and bonding among network players to provide the basis for the 
generation of network dynamics. However, the experience of the TH Alliance shows, if in a limited way, the significance of the contributions that players from the knowledge and government spheres in the triple helix network can make to promote the development of industrial activities through the process of knowledge acquisition and transformation. For instance, some SMEs realised the benefits of engagement with actors on the triple helix network and continued to pursue this engagement in spite of their earlier experience with their MNC client and FIBO, the university-based brokering intermediary. There is, however, no evidence to show that this continued networking engagement was a success. What is theoretically and empirically valid is that network development based on trust and the accumulation of social capital is crucial for the development of triple helix networks and their ultimate evolution into the triple helix innovation system. The converse is also true - that lack of trust would fragment networks or render them sterile and incapable of evolving into the triple helix system through dynamic learning via the processes of bridging and closure of structural holes.

The problem in developing countries is one of determining where governmentdriven, top-down initiatives should stop to give way to bottom-up and grassrootsbased initiatives in network development. In either case, knowledge intermediaries are necessary to promote network development as sponsors, brokers and boundaryspanners. But knowledge intermediaries would be effective when they are more disposed to the bottom-up than to the top-down culture of decision-making systems. It can, therefore, be argued that governments in developing countries would create less of a burden on themselves and contribute significantly more to the development of knowledge networks, in general, and triple helix networks, in particular, if they promoted market-oriented intermediaries to provide bridging and closure services in 
network development. Thus, for example, venture capital can be called in to serve as sponsors, while universities and private consultants can be trusted to intermediate as brokers and boundary spanners. This arrangement would have a transformative effect on the culture underlying the functions of the triple helix institutional actors industry would aspire to be innovative and competitive in its role as the agent of wealth creation; universities would seek to be entrepreneurial in their role as producers of knowledge and places of useful learning; and governments would seek to provide broad policy frameworks and regulatory measures to enable institutional players interact to exchange knowledge and generate innovation on a sustainable basis.

\section{Acknowledgements}

This paper is based on a larger study on knowledge network development in Thailand funded by the Thai Government that culminated in the $\mathrm{PhD}$ thesis of the lead author. An earlier version of the paper was presented at the $12^{\text {th }}$ International Triple Helix Conference 2013, London, 8-10 July, 2013. The authors would like to thank the Royal Thai Government and also the Department of Civil and Environmental Engineering at the University of Strathclyde for the support offered to facilitate completion of the study.

\section{References}

Ahuja, G. (2000). Collaboration Networks, Structural Holes, and Innovation: A Longitudinal Study. Administrative Science Quarterly, 45(3), 425-455.

Argyris, C. (1992). On Organisational Learning. Oxford: Blackwell.

Argyris, C. (1994). Good communication that blocks learning. Harvard Business Review, July-August, 77-85.

Argyris, C., Putnam, R. and McLain Smith, D. (1985). Action Science: Concepts, Methods and Skills for Research and Intervention. San Francisco, CA: JosseyBass.

Argyris, C. and Schoen, D.A. (1978), Organisational Learning: A Theory of Action Research. Reading, MA: Addison Wesley.

Balthasar, A., Bättig, C., Thierstein, A. et al. (2000). "Developers": key actors of the innovation process. Types of developers and their contacts to institutions involved in research and development, continuing education and training, and the transfer of technology. Technovation, 20(10), 523-538.

Beckman, C. M. and Haunschild, P. R. (2002). Network Learning: The Effects of Partners' Heterogeneity of Experience on Corporate Acquisitions. Administrative Science Quarterly, 47(1), 92-124. 
Bell, M. and Albu, M. (1999). Knowledge Systems and Technological Dynamism in Industrial Clusters in Developing Countries. World Development, 27(9), 17151734.

Bryman, A. (2008). Social Research Methods (3rd ed.). Oxford: Oxford University Press.

Burt, R. S. (2000). The network structure of social capital. Research in Organizational Behavior, 22, 345-423.

Burt, R. S. (2001). Structural Holes versus Network Closure as Social Capital. In Social Capital: Theory and Research (pp. 31-56): Aldine de Gruyter.

Burt, R. S. (2004). Structural Holes and Good Ideas. American Journal of Sociology, 110(2), 349-399.

Capaldo, A. (2007). Network structure and innovation: The leveraging of a dual network as a distinctive relational capability. Strategic Management Journal, 28(6), 585-608.

CPMO. (2011). Strategic Planning Alliance II: Hard disk drive programme. Retrieved. from.

Diao, X., Rattsø, J. and Stokke, H. E. (2006). Learning by exporting and structural change: A Ramsey growth model of Thailand. Journal of Policy Modeling, 28(3), 293-306.

Dosi, G. (1982). Technological paradigms and technological trajectories : A suggested interpretation of the determinants and directions of technical change. Research Policy, 11(3), 147-162.

Etzkowitz, H. and Dzisah, J. (2008). Rethinking development: circulation in the triple helix. Technology Analysis \& Strategic Management, 20(6), 653.

Fernandez, R. M. and Gould, R. V. (1994). A Dilemma of State Power: Brokerage and Influence in the National Health Policy Domain. American Journal of Sociology, 99(6), 1455-1491.

Flood, R.M. and Romm, N.R.A. (1996). Diversity Management: Triple Loop Learning. Chichester: John Wiley \& Sons Ltd.

Freeman, C. (1991). Networks of innovators: A synthesis of research issues. Research Policy, 20(5), 499-514.

Gemünden, H. G., Ritter, T. and Heydebreck, P. (1996). Network configuration and innovation success: An empirical analysis in German high-tech industries. International Journal of Research in Marketing, 13(5), 449-462.

Gilsing, V. (2005). The dynamics of innovation and interfirm networks : exploration, exploitation and co-evolution: Cheltenham UK ; Northampton, Mass. : Edward Elgar Publishing.

Harryson, S. J., Dudkowski, R. and Stern, A. (2008). Transformation Networks in Innovation Alliances: The Development of Volvo C70. Journal of Management Studies, 45(4), 745-773.

Johnson, W. H. A. (2009). Intermediates in triple helix collaboration: the roles of 4th pillar organisations in public to private technology transfer. International Journal of Technology Transfer and Commercialisation, 8, 142-158.

Kim, K., Choi, Y., Choi, C. Y. et al. (2010). The role of intermediaries on technological risk management and business development performance in Korea. Technological Forecasting and Social Change, 77(6), 870-880.

Knorringa, P. and van Staveren, I. (2006). Social capital for industrial development: operationalizing the concept. Vienna: United Nations Industrial Development Organization. 
Kohpaiboon, A. (2009). Hard disk drive industry in Thailand: International Production Network versus Industrial Clusters. Paper presented at the Singapore Economic Review ConferenceSingapore.

LewinA.Y.,Massini, S. and Peters, C. (2011). Micro-foundations of internal and external absorptive capacity routines. Organisation Science, 22(1), 81-98.

Leydesdorff, L. and Zawdie, G. (2010). The triple helix perspective of innovation systems. Technology Analysis \& Strategic Management, 22(7), 789-804.

Madill, J. J., Haines, G. H. and Riding, A. L. (2004). Networks and linkages among firms and organizations in the Ottawa-region technology cluster.

Entrepreneurship \& Regional Development: An International Journal, 16(5), $351-368$.

Mason, R.M. (1993).Strategic information systems: use of information technology in learning organisation. Proceedings of the $26^{\text {th }}$ HawaiiInternational Conference on System Sciences, 5-8 January. Wailea, HI.

Menzel, M.-P. and Fornahl, D. (2007). Cluster Life Cycles - Dimensions and Rationales of Cluster Development [Electronic Version]. Jena Economic Reseach Papers.

Murdoch, J. (2000). Networks - a new paradigm of rural development? Journal of Rural Studies, 16(4), 407-419.

Nakwa, K. (2013). Innovation Intermediaries and Triple Helix Networks in Developing Countries with Particular Reference to the Case of Thailand. Glasgow: unpublished $\mathrm{PhD}$ thesis, University of Strathclyde.

Nakwa, K. and Zawdie, G. (2012). The role of innovation intermediaries in promoting the triple helix system in MNC-dominated industries in Thailand: the case of hard disk drive and automotive sectors. International Journal of Technology Management and Sustainable Development, 11(3), 265-283.

Nakwa, K., Zawdie, G. and Intarakumnerd, P. (2012). Role of Intermediaries in Accelerating the Transformation of Inter-Firm Networks into Triple Helix Networks: A Case Study of SME-based Industries in Thailand. Procedia Social and Behavioral Sciences, 52(0), 52-61.

Nevis, E.C., DiBella, A.J. and Gould, J.M. (1995). Understanding organisations as learning systems. Sloan Management Review, 36(2), 75-85.

Nonaka, I. and Takeuchi, H. (1995). The knowledge-creating company : how Japanese companies create the dynamics of innovation: New York : Oxford University Press.

Pahl-Wostl, C. (2009). A conceptual framework for analysing adaptive capacity and multi-level learning processes in resource governance regimes. Global Environmental Change, 19(3), 354-365.

Pöyhönen, A. and Smedlund, A. (2004). Assessing intellectual capital creation in regional clusters. Journal of Intellectual Capital, 5(3), 351-365.

Promwong, K. (2001). An Analysis of the Sources of Productivity Growth and Competitiveness in Thailand's Manufacturing Sector. Glasgow: unpublished $\mathrm{PhD}$ thesis, University of Strathclyde.

Pyka, A. (2002). Innovation networks in economics: from the incentive-based to the knowledge-based approaches. European Journal of Innovation Management, 5(3), 152-163.

Robertson, P. L. and Langlois, R. N. (1995). Innovation, networks, and vertical integration. Research Policy, 24(4), 543-562.

Snell, R. and Chak, A. M.K. (1998). The learning organisation: Learning and empowerment for whom? Management Learning, 29 (3), 337-364. 
(Date of acceptance 24/02/2014) 